\title{
Excess Body Weight and Gallstone Disease
}

\author{
Caroline Sarah Stokes ${ }^{a, b}$ Frank Lammert ${ }^{c, d}$ \\ ${ }^{a}$ Food and Health Research Group, Faculty of Life Sciences, Humboldt University Berlin, Berlin, Germany; ${ }^{\mathrm{b}}$ Research \\ Group Nutrients and Health, Department of Molecular Toxicology, German Institute of Human Nutrition, Potsdam- \\ Rehbrücke, Germany; ' Department of Medicine II, Saarland University Medical Center, University of Saarland,

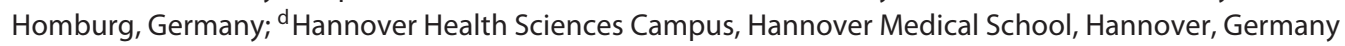

\section{Keywords}

Bariatric surgery · Cholecystectomy · Cholelithiasis · Diet · Obesity

\begin{abstract}
Background: Approximately one fifth of adults are diagnosed with gallstones worldwide. Of these, around $25 \%$ develop gallstone disease (indicated by the presence of symptoms) and undergo cholecystectomy. Summary: The risk of gallstones is influenced by a combination of genetic and lifestyle factors, such as excess body weight. In fact, body mass has been demonstrated to be a major risk factor for symptomatic gallstones. Rapid weight loss can also initiate a prolithogenic state and further increase the likelihood of either gallstone formation or existing gallstones becoming symptomatic; however, sensible weight loss strategies can mitigate this risk. This review discusses the role of excess body weight and the risk of gallstone disease, as well as the options available for the prevention of symptomatic gallstones. Key Messages: Healthy weight loss diets combined with regular physical activity can promote successful weight loss and weight maintenance and reduce the risk of gallstones. Should rapid weight loss be required for health reasons or be expected, e.g., after bariatric surgery, prophylactic ursodeoxycholic acid during the period of weight reduction has been demonstrated to reduce the incidence of gallstones formation or symptomatic gallstone occurrence. The recent German guidelines on gallstones recommend simultaneous cholecystectomy during bariatric surgery but only for those
\end{abstract} with preexisting symptomatic stones.

(C) 2021 The Author(s)

Published by S. Karger AG, Basel

\section{Introduction}

The global prevalence of gallstones has been reported to be up to $20 \%$ in adults [1]. The identification of gallstones per se does not necessitate treatment, as the majority of individuals with stones remain asymptomatic. However, approximately $25 \%$ develop symptoms and/or complications $[2,3]$ and are therefore diagnosed as having gallstone disease, for which (laparoscopic) cholecystectomy (gallbladder removal) is the gold standard treatment [1].

Gallstones are classified based on their localization (gallbladder or biliary tract) and composition, which is determined by physical-chemical alterations in bile, and differentiated by elevated cholesterol or bilirubin concentrations. Approximately $90 \%$ of gallstones are cholesterol stones and primarily composed of cholesterol [4]. The remaining $10 \%$ are made up of black and brown pigment stones which are mainly composed of calcium bilirubinate, calcium complexes, and mucin glycoproteins, or unconjugated bilirubin, respectively [4].

The risk of gallstones entails a combination of both nonmodifiable (genetic) and modifiable (environmental/ lifestyle) factors. Genetic variants have been determined to account for approximately a quarter of the overall gallstone risk [5]. The most commonly reported genetic risk factor in humans identified in genome-wide association studies is the ABCG8 p.D19H variant of the hepatocanalicular cholesterol transporter, a heterodimer of ATPbinding cassette transporters [6]. Modifiable risks entail a combination of factors such as body weight, parity, metabolic aberrations including obesity, hyperinsulinemia, 
insulin resistance, and diabetes, or physical inactivity and energy-dense nutrition, including increased consumption of refined carbohydrates and saturated fats and a limited intake of fiber. In addition, certain medications, such as estrogens and progesterone, can predispose to lithogenic states [7]. This review focuses on the modifiable risk and prevention options for gallstones related to obesity in adults.

\section{Body Weight and Gallstones}

Increased body weight is an established risk factor for gallstone formation, and indeed an increased BMI has been demonstrated to be causally linked to the risk of symptomatic stones, as illustrated in a mendelian randomization study in 77,679 individuals [8]. This report showed symptomatic gallstones in 5.2\% (4,106 individuals) of cases in up to 34 years of follow-up, with the findings being more distinct in women. The distribution of body fat also affects the risk of gallstones, with prospective cohort studies showing an association between gallstone formation and central adiposity as compared to limb or lower-extremity adiposity [9]. The increased risk associated with abdominal adiposity can occur independently of BMI, as illustrated in 2 cohorts from the USA $[10,11]$. Both obesity and abdominal obesity increase the risk not only of stone formation but also of requiring surgical treatment (cholecystectomy) because of the higher likelihood of presenting with symptomatic stones [10, 12, 13]. Abdominal adiposity is associated with insulin resistance which, given its stimulating effects on hepatic cholesterol secretion, is reported as a key factor in gallstone formation [14].

The influence of body weight on gallstones has also recently been suggested to occur independently of age. For example, a retrospective cross-sectional Asian study [15] observed participants younger than 50 years to have a higher risk of gallstones $(\mathrm{OR}=5.4 ; 95 \% \mathrm{CI} 2.3-12.7)$ if they were obese and showed features of the metabolic syndrome. Here, obesity was defined as a BMI >25 for Asians [16]. Features of the metabolic syndrome were defined according to a set of accepted unified criteria [see full details in 17]. Moreover, the prevalence of gallstones in individuals younger than 50 years with obesity and metabolic syndrome was identical to the prevalence of gallstones in elderly people who were metabolically healthy and not obese.

The pathophysiological mechanisms that increase the risk of gallstones with excess body fat are multifactorial. The primary risk is the occurrence of cholesterol gallstones, which result from the accumulation of cholesterol monohydrate crystals precipitating in gallbladder bile containing excess cholesterol as compared to bile salts and phospholipids [18]. This excess cholesterol is secreted by hepatocytes as a direct result of increased body weight. Thus, increased body fat is lithogenic [19], and the higher the body weight, the greater the risk of cholesterol stones in the gallbladder [12]. It has been estimated that each extra kilogram of body fat yields the production of approximately $20 \mathrm{mg}$ of additional cholesterol. This excess cholesterol contributes to the saturation of bile with cholesterol and, accordingly, cholesterol supersaturation of gallbladder bile has been documented in obese patients but not in nonobese controls [20]. Increased body weight is additionally associated with reduced gallbladder motility, another factor that contributes to stone production [21].

More recently, a Chinese study observed higher concentrations of (high-sensitivity) $\mathrm{C}$ reactive protein (CRP) to be an independent risk factor for new-onset cholesterol gallstones [22]. Specifically, a high-sensitivity CRP concentration $>3 \mathrm{mg} / \mathrm{L}$ was associated with a $12 \%$ increased risk of stones. Currently, it remains unknown how elevated CRP increases the risk of gallstones; however, it has been suggested as being associated with obesity, where secretion of the proinflammatory cytokine interleukin-6 (an upstream stimulator of CRP production in the liver) is stimulated by adipose tissue and contributes to systemic inflammation in obesity $[23,24]$.

\section{Rapid Weight Loss and Weight Cycling}

In general, weight loss reduces the risk of gallstones, with the exception of 2 specific settings: weight loss that is extremely rapid (i.e., $>1.5 \mathrm{~kg} /$ week) and excessive weight reduction (i.e., $>25 \%$ body weight) [25-27]. In both of these cases, the risk of gallstones occurring increases $[28,29]$. Rapid weight loss can predispose to a lithogenic state and subsequently the formation of gallstones [27]. In addition, weight loss induced after bariatric surgery has been reported to initiate biliary sludge (composed of precipitated lipid particles such as aggregated crystals or microliths) and gallstones in 30\% of cases during the 6-month period after receiving a gastric bypass or biliopancreatic diversion $[30,31]$. A comparable incidence $(30 \%)$ of gallstones after sleeve gastrectomy was reported at 6-12 months postsurgery in a prospective study [32]. These risks, however, have not been reported with laparoscopic gastric banding [33].

Weight cycling (i.e., weight that is lost and regained) is an independent risk factor for gallstones [34-36]. Weight fluctuations also increase the risk of requiring a cholecystectomy [35]. Syngal et al. [35] observed both moderate $(4.5-8.5 \mathrm{~kg})$ and severe $(\geq 9 \mathrm{~kg})$ fluctuations in a single weight cycle to increase the risk of cholecystectomy by 31 and $68 \%$, respectively. Alterations of the ratio of choles- 
terol to bile salts within the gallbladder were observed in the setting of weight fluctuations and in rapid weight loss [37], reflecting increased hepatic cholesterol secretion and synthesis as well as a reduced secretion of bile salts [18]. An impairment in gallbladder motility also occurs, which triggers the formation of biliary sludge $[37,38]$.

\section{Prevention and Treatment of Gallstones in Obesity}

\section{The Role of Cholecystectomy}

Cholecystectomy is the gold standard treatment for symptomatic gallstones, and it is often but not routinely carried out during bariatric surgery in obese patients. There has been a reduction in the rate of simultaneous cholecystectomies in recent years due to the morbidity and mortality associated with the procedure as well as a high reintervention risk [39]. Studies have reported concomitant cholecystectomy to result in longer operation times, longer hospital stays, and higher complication rates $[39,40]$. The risk of secondary cholecystectomy was demonstrated to be $6.8 \%$ (with $5.3 \%$ of these cases presenting with symptoms) after laparoscopic Roux-en-Y reconstruction, as reported in a meta-analysis of 13 studies, 12 of which were retrospective [41]. Other studies have shown the incidence of cholecystectomy to range from 3.3 and $14.7 \%$ in the 6-24 months after bariatric surgery $[42,43]$. Generally, the morbidity and mortality for cholecystectomy in obese patients not undergoing bariatric surgery do not appear to be higher than those of the general population [44]. There have been previous reports of increased procedure times and postoperative morbidities in obesity; however, these did not differ significantly compared to non-obese controls [45]. Recently, Reeves et al. [44] reported a small increased odds of hospital admissions in patients with severe morbid obesity (BMI >50) compared to patients with a BMI between 30 and 40 , but this increased risk was only modest (OR = 1.10; 95\% CI 1.02-1.19; $p<0.001$ ).

As such, the recent German consensus guidelines for gallstone disease recommend simultaneous cholecystectomy only in obese patients with symptomatic gallstones $[39,46]$, as do the European guidelines [47]. These risks do, however, differ depending on the type of bariatric surgery, with the laparoscopic Roux-en-Y surgery displaying a higher risk than either gastric banding or sleeve resection [48]. Two recent studies corroborated the guideline recommendations; Della Penna et al. [49] followed up 61 patients with asymptomatic gallstones treated with ursodeoxycholic acid (UDCA) for 6 months after bariatric surgery (either laparoscopic Roux-en-Y gastric bypass or sleeve gastrectomy). Cholecystectomy was required in 1 patient only who had undergone sleeve gastrectomy. Another patient reported symptoms during the 6-month fol- low-up after sleeve gastrectomy but did not require cholecystectomy. The remaining 59 patients remained asymptomatic with UDCA prophylaxis.

The Swedish Obese Subjects study [50] also supports the recent guidelines, reporting an overall low cumulative incidence for cholecystectomy after bariatric surgery. This nonrandomized, controlled study compared standard of care with the effects of bariatric surgery [50]. Overall, 3,597 participants who had not undergone previous or concomitant cholecystectomy at the time of inclusion were analyzed. The cohort was divided into 2 groups: 1,755 patients received bariatric surgery (gastric bypass, $n=236$; vertical banded gastroplasty, $n=1,202$; and gastric banding, $n=317)$. The control group $(n=1,842)$ received the usual treatment for obesity, including lifestyle advice. UDCA was not provided to any of the groups. During 26 years of follow-up, modest weight changes were observed in the control group (3\% fluctuations), in contrast to the surgical group where weight loss averaged $25 \%$ at 2 years and $16 \%$ at both 10 and 15 years. Symptomatic gallstone incidence differed significantly $(p<$ 0.001 ), with the surgery group reporting 307 first-time events versus 252 in the controls. A similar trend was observed for complicated gallstones and the rate of cholecystectomies, with 172 versus 144 first-time events $(p<$ $0.006)$ and 230 versus 170 cases $(p<0.001)$, respectively. The above risks were more pronounced during the first 5 years after surgery.

Given the invasiveness of the standard treatment for gallstone disease, a greater emphasis on the prevention of gallstones is required and it is discussed in the following sections within the context of excess body weight.

\section{Diet and Physical Activity}

Steady weight reduction (i.e., $<1.5 \mathrm{~kg} /$ week) is recommended in the setting of obesity and gallstone risks (as discussed in Rapid Weight Loss and Weight Cycling). The increased risks of gallstones have been illustrated with 2 popular weight reduction methods, i.e., bariatric surgery and very low-calorie diets $[26-28,51]$, with approximate risks of 30 and $25 \%$, respectively [26, 28]. Randomized controlled trials in obese patients have demonstrated these risks to be mitigated to a certain degree when weight loss diets have a higher fat content $[37,52,53]$. General nutrition-related recommendations include reducing the energy density of the diet (particularly avoiding saturated fats and sugar) and instead consuming fiber-rich foods such as wholegrains, fruits, or vegetables [54-59]. Reducing energy-dense foods, particularly those high in sugar, has shown beneficial effects on both weight and gallstone risk [60]. A high dietary glycemic load increases the risk of gallbladder stone formation [61-63]. In contrast, fiber-rich foods reduce the risk of cholecystectomy in women $[64,65]$. Additionally, a reduction in the 


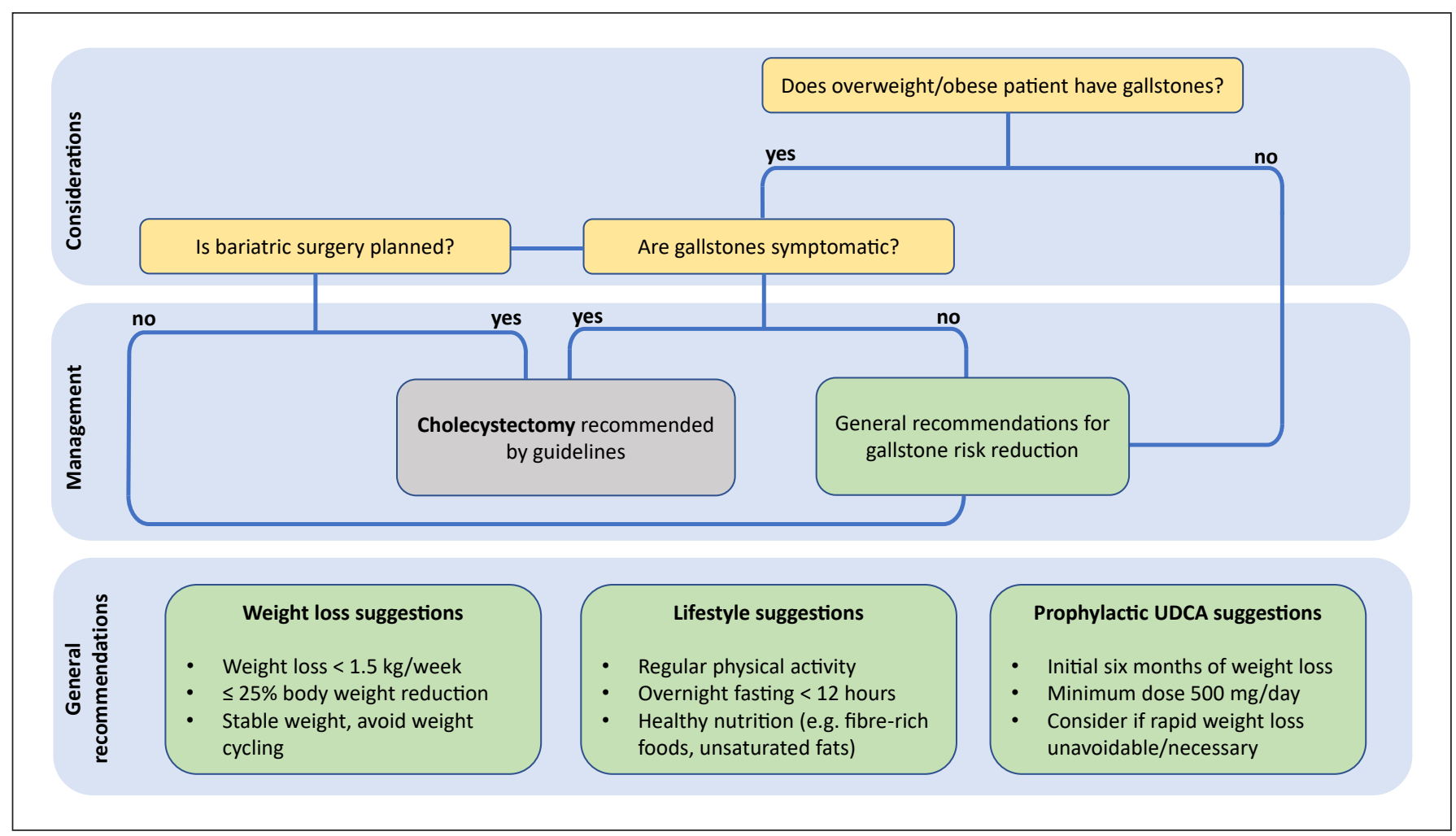

Fig. 1. Suggested approach based on clinical evidence and guideline recommendations to reduce the risk of gallstone disease in overweight/obese patients undergoing weight loss.

lithogenicity of hydrophobic bile salts was demonstrated with consumption of high-fiber and calcium-rich foods [66]. However, fiber supplementation during weight loss did not lead to significant benefits in terms of gallstone development in a randomized study with obese participants [67]. Other foods reported to reduce the risk of cholecystectomy include legumes, olive oil [68], and nuts [69].

Dietary lipids are mediators of gallstone risk, with unsaturated fatty acids displaying risk reduction properties and saturated and trans fats increasing the risk [70-72]. In patients with gallstones, omega- 3 fatty acid supplementation reduced the cholesterol saturation index in bile [73]. Another study in obese women without gallstones who were randomized to receiving omega- 3 fatty acids or UDCA or placebo for 6 weeks did not observe a reduction of biliary cholesterol saturation, despite the fact that none of the participants developed gallstones during this intervention period [74]. The omega-3 group did, however, display improved gallbladder motility in patients with hypertriglyceridemia [75]. Additionally, gallbladder hypomotility might be mitigated by reducing the time of overnight fasting to less than $12 \mathrm{~h}$, as suggested by observational data [76].

Physical activity has a multitude of benefits with regard to weight loss and weight maintenance, and it has also been studied for its direct effects on gallstone risk. In fact, several studies have reported physical activity as having protective effects on the formation of gallstones [34, $63,77-79]$. Intervention studies, however, show only modest effects: improvements in gallbladder motility were observed in a randomized study, where the intervention included moderate training, but the results were similar in the control group [80]. A lack of significant effects on gallstones was also reported in pregnant women taking part in a randomized study [81].

\section{Prophylactic Ursodeoxycholic Acid}

During the weight reduction phase, prophylactic ursodeoxycholic acid has shown great promise in reducing the formation of gallstones regardless of the method of weight loss, i.e., low-calorie diets or bariatric surgery, with reductions as high as $58 \%$ reported in randomized controlled trials [25, 29, 31, 53, 82-85]. A minimum dose of $500 \mathrm{mg} /$ day is recommended, as shown in clinical trials and a meta-analysis of such trials, with this dose being more effective than $300 \mathrm{mg} /$ day in reducing the risk of gallstones forming during a 6 -week period but also after 3-4 months [53]. A higher dose has not shown greater benefits either, as illustrated in a randomized trial in patients receiving gastric bypass [31]. In this study, 3 UDCA doses were compared: 300, 600 and 1,200 mg/day for 6 months. The 
600-mg dose was the most efficacious at preventing gallstones, with an incidence of 2 versus 13 and $6 \%$ in those receiving 300 and $1,200 \mathrm{mg}$, respectively. These findings have been corroborated [29].

Since subsequent cholecystectomy, e.g. after bariatric surgery, can be performed should gallstones become symptomatic, many patients do not receive prophylactic UCDA during the weight reduction phase in clinical practice [86, 87]. Given the benefits reported above, recent guidelines on gallstones have strongly recommended UDCA be given as a prophylaxis in the case of a high risk of sludge or stone formation when undergoing weight loss either through low-calorie diets or bariatric surgery $[46,47]$. Studies suggest the first 6 months after surgery to be the most critical because they are associated with the greatest reduction in body weight, with UDCA showing mild benefits after the first 6 months that do not justify prolonged prophylaxis [88]. A recent randomized study assessed the effects of prophylactic UDCA on the incidence of gallstones in 190 patients undergoing 1 anastomosis gastric bypass [89]. These patients were randomized to either $600 \mathrm{mg} /$ day of oral UDCA $(n=95)$ or to a control group $(n=95)$ for 6 months. The incidence of gallstones after 3 months was 0 versus $4(4.2 \%)$ in the UDCA and control groups, respectively, and 3 (3.1\%) versus $21(22.1 \%)$ at 6 months. After 12 months of followup, $4(4.2 \%)$ versus $24(25.2 \%)$ patients in the UDCA and control groups developed gallstones, respectively $(p<$ $0.05)$. The majority were asymptomatic, with only $28.6 \%$ of participants displaying symptoms. Multivariate analyses identified UDCA as the only significant predictor of gallstone formation $(\mathrm{HR}=0.17 ; 95 \% \mathrm{CI} 0.06-0.48 ; p<$ $0.001)$.

\section{Conclusions}

Excess body weight is associated with an increased risk of cholesterol gallstones. As summarized in Figure 1, sensible weight loss strategies can mitigate this risk, but rapid weight loss or weight cycling might trigger a lithogenic cascade and further increase the probability of either gallstones forming or of stones becoming symptomatic. Healthy nutrition with an emphasis on plant foods and unsaturated fats combined with regular physical activity can promote successful weight loss and weight maintenance. In the case of rapid weight loss, such as in the setting of bariatric surgery, prophylactic UDCA during the initial 6 months has been demonstrated to reduce the incidence of both gallstones and biliary symptoms. Such a strategy should benefit patients who are candidates for bariatric surgery or who for other health reasons need to undergo rapid weight loss, since recent guidelines do not recommend simultaneous cholecystectomy during surgery unless the patient has a preexisting diagnosis of symptomatic gallstones.

\section{Conflict of Interest Statement}

The authors of the present review have nothing to declare.

\section{Funding Sources}

No funding was received for the preparation of this review.

\section{Author Contributions}

Both of the authors drafted and revised this paper.

\section{References}

1 Everhart JE, Ruhl CE. Burden of digestive diseases in the United States Part III: Liver, biliary tract, and pancreas. Gastroenterology. 2009 Apr;136(4):1134-44.

2 Portincasa P, Ciaula AD, Bonfrate L, Wang DQ. Therapy of gallstone disease: what it was, what it is, what it will be. World J Gastrointest Pharmacol Ther. 2012 Apr;3(2):7-20.

3 Attili AF, De Santis A, Capri R, Repice AM, Maselli S, Group G; The GREPCO Group. The natural history of gallstones: the GREPCO experience. Hepatology. 1995 Mar;21(3):655-60.

4 Schafmayer C, Hartleb J, Tepel J, Albers S, Freitag S, Völzke H, et al. Predictors of gallstone composition in 1025 symptomatic gallstones from Northern Germany. BMC Gastroenterol. 2006 Nov;6(1):36.
5 Katsika D, Grjibovski A, Einarsson C, Lammert F, Lichtenstein P, Marschall HU. Genetic and environmental influences on symptomatic gallstone disease: a Swedish study of 43,141 twin pairs. Hepatology. 2005 May;41(5):1138-43.

6 Lammert F, Sauerbruch T. Mechanisms of disease: the genetic epidemiology of gallbladder stones. Nat Clin Pract Gastroenterol Hepatol. 2005 Sep;2(9):423-33.

7 Lammert F, Gurusamy K, Ko CW, Miquel JF, Méndez-Sánchez N, Portincasa P, et al. Gallstones. Nat Rev Dis Primers. 2016 Apr;2(1):16024.

8 Stender S, Nordestgaard BG, Tybjaerg-Hansen A. Elevated body mass index as a causal risk factor for symptomatic gallstone disease: a Mendelian randomization study. Hepatology. 2013 Dec;58(6):2133-41.
9 Haffner SM, Diehl AK, Stern MP, Hazuda HP. Central adiposity and gallbladder disease in Mexican Americans. Am J Epidemiol. 1989 Mar;129(3):587-95.

10 Tsai CJ, Leitzmann MF, Willett WC, Giovannucci EL. Central adiposity, regional fat distribution, and the risk of cholecystectomy in women. Gut. 2006 May;55(5):708-14.

11 Tsai CJ, Leitzmann MF, Willett WC, Giovannucci EL. Prospective study of abdominal adiposity and gallstone disease in US men. Am J Clin Nutr. 2004 Jul;80(1):38-44.

12 Maclure KM, Hayes KC, Colditz GA, Stampfer MJ, Speizer FE, Willett WC. Weight, diet, and the risk of symptomatic gallstones in middle-aged women. N Engl J Med. 1989 Aug;321(9):563-9. 
13 Völzke H, Baumeister SE, Alte D, Hoffmann W, Schwahn C, Simon P, et al. Independent risk factors for gallstone formation in a region with high cholelithiasis prevalence. Digestion. 2005;71(2):97-105.

14 Nakeeb A, Comuzzie AG, Al-Azzawi H, Sonnenberg GE, Kissebah AH, Pitt HA. Insulin resistance causes human gallbladder dysmotility. J Gastrointest Surg. 2006 JulAug;10(7):940-8.

15 Su PY, Hsu YC, Cheng YF, Kor CT, Su WW. Strong association between metabolically-abnormal obesity and gallstone disease in adults under 50years. BMC Gastroenterol. 2019 Jul;19(1):117.

$16 \mathrm{WHO} / \mathrm{IASO} / \mathrm{IOTF}$. The Asia-Pacific perspective: redefining obesity and its treatment Melbourne: Health Communications Australia; 2000.

17 Alberti KG, Eckel RH, Grundy SM, Zimmet PZ, Cleeman JI, Donato KA, et al.; International Diabetes Federation Task Force on Epidemiology and Prevention; Hational Heart, Lung, and Blood Institute; American Heart Association; World Heart Federation; International Atherosclerosis Society; International Association for the Study of Obesity. Harmonizing the metabolic syndrome: a joint interim statement of the International Diabetes Federation Task Force on Epidemiology and Prevention; National Heart, Lung, and Blood Institute; American Heart Association; World Heart Federation; International Atherosclerosis Society; and International Association for the Study of Obesity. Circulation. 2009 Oct;120(16):1640-5.

18 Portincasa P, Moschetta A, Palasciano G. Cholesterol gallstone disease. Lancet. 2006 Jul;368(9531):230-9.

19 Sahi T, Paffenbarger RS, Hsieh CC, Lee IM. Body mass index, cigarette smoking, and other characteristics as predictors of self-reported, physician-diagnosed gallbladder disease in male college alumni. Am J Epidemiol. 1998 Apr;147(7):644-51.

20 Freeman JB, Meyer PD, Printen KJ, Mason EE, DenBesten L. Analysis of gallbladder bile in morbid obesity. Am J Surg. 1975 Feb;129(2):163-6.

21 Di Ciaula A, Wang DQ, Portincasa P. Gallbladder and gastric motility in obese newborns, pre-adolescents and adults. J Gastroenterol Hepatol. 2012 Aug;27(8):1298-305.

22 Liu T, Siyin ST, Yao N, Duan N, Xu G, Li W, et al. Relationship between high-sensitivity $\mathrm{C}$ reactive protein and the risk of gallstone disease: results from the Kailuan cohort study. BMJ Open. 2020 Sep;10(9):e035880.

23 Kwaifa IK, Bahari H, Yong YK, Noor SM. Endothelial Dysfunction in Obesity-Induced Inflammation: Molecular Mechanisms and Clinical Implications. Biomolecules. 2020 Feb;10(2):291.

24 Cozma A, Orăşan O, Sâmpelean D, Fodor A, Vlad C, Negrean V, et al. Endothelial dysfunction in metabolic syndrome. Rom J Intern Med. 2009;47(2):133-40.

25 Broomfield PH, Chopra R, Sheinbaum RC, Bonorris GG, Silverman A, Schoenfield LJ, et al. Effects of ursodeoxycholic acid and aspirin on the formation of lithogenic bile and gallstones during loss of weight. N Engl J Med. 1988 Dec;319(24):1567-72.
26 Liddle RA, Goldstein RB, Saxton J. Gallstone formation during weight-reduction dieting. Arch Intern Med. 1989 Aug;149(8):1750-3.

27 Weinsier RL, Wilson LJ, Lee J. Medically safe rate of weight loss for the treatment of obesity: a guideline based on risk of gallstone formation. Am J Med. 1995 Feb;98(2):115-7.

28 Li VK, Pulido N, Fajnwaks P, Szomstein S, Rosenthal R, Martinez-Duartez P. Predictors of gallstone formation after bariatric surgery: a multivariate analysis of risk factors comparing gastric bypass, gastric banding, and sleeve gastrectomy. Surg Endosc. 2009 Jul;23(7):1640-4.

29 Shiffman ML, Kaplan GD, Brinkman-Kaplan V, Vickers FF. Prophylaxis against gallstone formation with ursodeoxycholic acid in patients participating in a very-low-calorie diet program. Ann Intern Med. 1995 Jun;122(12):899-905.

30 Shiffman ML, Sugerman HJ, Kellum JH, Brewer WH, Moore EW. Gallstones in patients with morbid obesity. Relationship to body weight, weight loss and gallbladder bile cholesterol solubility. Int J Obes Relat Metab Disord. 1993 Mar;17(3):153-8.

31 Sugerman HJ, Brewer WH, Shiffman ML, Brolin RE, Fobi MA, Linner JH, et al. A multicenter, placebo-controlled, randomized, double-blind, prospective trial of prophylactic ursodiol for the prevention of gallstone formation following gastric-bypass-induced rapid weight loss. Am J Surg. 1995 Jan;169(1):91-6

32 Adams LB, Chang C, Pope J, Kim Y, Liu P, Yates A. Randomized, Prospective Comparison of Ursodeoxycholic Acid for the Prevention of Gallstones after Sleeve Gastrectomy. Obes Surg. 2016 May;26(5):990-4.

33 O'Brien PE, Dixon JB. A rational approach to cholelithiasis in bariatric surgery: its application to the laparoscopically placed adjustable gastric band. Arch Surg. 2003 Aug;138(8):908-12

34 Ortega RM, Fernández-Azuela M, EncinasSotillos A, Andrés P, López-Sobaler AM. Differences in diet and food habits between patients with gallstones and controls. J Am Coll Nutr. 1997 Feb;16(1):88-95.

35 Syngal S, Coakley EH, Willett WC, Byers T, Williamson DF, Colditz GA. Long-term weight patterns and risk for cholecystectomy in women. Ann Intern Med. 1999 Mar;130(6):471-7.

36 Tsai CJ, Leitzmann MF, Willett WC, Giovannucci EL. Weight cycling and risk of gallstone disease in men. Arch Intern Med. 2006 Nov;166(21):2369-74

37 Gebhard RL, Prigge WF, Ansel HJ, Schlasner L, Ketover SR, Sande D, et al. The role of gallbladder emptying in gallstone formation during diet-induced rapid weight loss. Hepatology. 1996 Sep;24(3):544-8.

38 Shiffman ML, Sugerman HJ, Kellum JM, Moore EW. Changes in gallbladder bile composition following gallstone formation and weight reduction. Gastroenterology. 1992 Jul;103(1):214-21.

39 Worni M, Guller U, Shah A, Gandhi M, Shah J, Rajgor D, et al. Cholecystectomy concomitant with laparoscopic gastric bypass: a trend analysis of the nationwide inpatient sample from 2001 to 2008. Obes Surg. 2012 Feb;22(2):220-9.
40 Hamad GG, Ikramuddin S, Gourash WF, Schauer PR. Elective cholecystectomy during laparoscopic Roux-en-Y gastric bypass: is it worth the wait? Obes Surg. 2003 Feb;13(1):7681.

41 Warschkow R, Tarantino I, Ukegjini K, Beutner U, Güller U, Schmied BM, et al. Concomitant cholecystectomy during laparoscopic Roux-en-Y gastric bypass in obese patients is not justified: a meta-analysis. Obes Surg. 2013 Mar;23(3):397-407.

42 Kim JJ, Schirmer B. Safety and efficacy of simultaneous cholecystectomy at Roux-en-Y gastric bypass. Surg Obes Relat Dis. 2009 JanFeb;5(1):48-53.

43 Swartz DE, Felix EL. Elective cholecystectomy after Roux-en-Y gastric bypass: why should asymptomatic gallstones be treated differently in morbidly obese patients? Surg Obes Relat Dis. 2005 Nov-Dec;1(6):555-60.

44 Reeves JJ, Burton BN, Broderick RC, et al Obesity and unanticipated hospital admission following outpatient laparoscopic cholecystectomy. Surg Endosc. 2021 Mar;35(3):1348-54.

45 Ammori BJ, Vezakis A, Davides D, Martin IG, Larvin M, McMahon MJ. Laparoscopic cholecystectomy in morbidly obese patients. Surg Endosc. 2001 Nov;15(11):1336-9.

46 Gutt C, Jenssen C, Barreiros AP, Götze TO, Stokes CS, Jansen PL, et al. Aktualisierte S3Leitlinie der Deutschen Gesellschaft für Gastroenterologie, Verdauungs- und Stoffwechselkrankheiten (DGVS) und der Deutschen Gesellschaft für Allgemein- und Viszeralchirurgie (DGAV) zur Prävention, Diagnostik und Behandlung von Gallensteinen. Z Gastroenterol. 2018 Aug;56(8):912-66.

47 Lammert F, Acalovschi M, Ercolani G, van Erpecum K, Gurusamy KS, van Laarhoven CJ, et al. EASL Clinical Practice Guidelines on the prevention, diagnosis and treatment of gallstones. J Hepatol. 2016 Jul;65(1):146-81.

48 Tsirline VB, Keilani ZM, El Djouzi S, Phillips RC, Kuwada TS, Gersin K, et al. How frequently and when do patients undergo cholecystectomy after bariatric surgery? Surg Obes Relat Dis. 2014 Mar-Apr;10(2):313-21.

49 Della Penna A, Lange J, Hilbert J, Archid R, Königsrainer A, Quante M. Ursodeoxycholic Acid for 6 Months After Bariatric Surgery Is Impacting Gallstone Associated Morbidity in Patients with Preoperative Asymptomatic Gallstones. Obes Surg. 2019 Apr;29(4):121621.

50 Anveden Å, Peltonen M, Näslund I, Torgerson J, Carlsson LM. Long-term incidence of gallstone disease after bariatric surgery: results from the nonrandomized controlled Swedish Obese Subjects study. Surg Obes Relat Dis. 2020 Oct;16(10):1474-82.

51 Kamrath RO, Plummer LJ, Sadur CN, Adler MA, Strader WJ, Young RL, et al. Cholelithiasis in patients treated with a very-low-calorie diet. Am J Clin Nutr. 1992 Jul;56(1 Suppl):255S-7S.

52 Festi D, Colecchia A, Orsini M, Sangermano A, Sottili S, Simoni P, et al. Gallbladder motility and gallstone formation in obese patients following very low calorie diets. Use it (fat) to lose it (well). Int J Obes Relat Metab Disord. 1998 Jun;22(6):592-600. 
53 Stokes CS, Gluud LL, Casper M, Lammert F. Ursodeoxycholic acid and diets higher in fat prevent gallbladder stones during weight loss: a meta-analysis of randomized controlled trials. Clin Gastroenterol Hepatol. 2014 Jul;12(7):1090-1100.e2

54 Malik VS, Schulze MB, Hu FB. Intake of sugar-sweetened beverages and weight gain: a systematic review. Am J Clin Nutr. 2006 Aug;84(2):274-88.

55 Vartanian LR, Schwartz MB, Brownell KD. Effects of soft drink consumption on nutrition and health: a systematic review and metaanalysis. Am J Public Health. 2007 Apr;97(4):667-75.

56 Harland JI, Garton LE. Whole-grain intake as a marker of healthy body weight and adiposity. Public Health Nutr. 2008 Jun;11(6):55463.

57 Savage JS, Marini M, Birch LL. Dietary energy density predicts women's weight change over 6 y. Am J Clin Nutr. 2008 Sep;88(3):677-84.

58 Bes-Rastrollo M, van Dam RM, MartinezGonzalez MA, Li TY, Sampson LL, Hu FB. Prospective study of dietary energy density and weight gain in women. Am J Clin Nutr. 2008 Sep;88(3):769-77.

59 Hooper L, Abdelhamid A, Moore HJ, Douthwaite W, Skeaff CM, Summerbell CD. Effect of reducing total fat intake on body weight: systematic review and meta-analysis of randomised controlled trials and cohort studies. BMJ. 2012 Dec;345:e7666.

60 Arbeitsgemeinschaft der Wissenschaftlichen Medizinischen Fachgesellschaften (AWMF). Interdisziplinäre Leitlinie der Qualität S3 zur Prävention und Therapie der Adipositas. Deutsche Adipositas-Gesellschaft, Martinsried 2014.

61 Tsai CJ, Leitzmann MF, Willett WC, Giovannucci EL. Glycemic load, glycemic index, and carbohydrate intake in relation to risk of cholecystectomy in women. Gastroenterology. 2005 Jul;129(1):105-12.

62 Tsai CJ, Leitzmann MF, Willett WC, Giovannucci EL. Dietary carbohydrates and glycaemic load and the incidence of symptomatic gall stone disease in men. Gut. 2005 Jun;54(6):823-8.

63 Misciagna G, Centonze S, Leoci C, Guerra V, Cisternino AM, Ceo R, et al. Diet, physical activity, and gallstones - a population-based, case-control study in southern Italy. Am J Clin Nutr. 1999 Jan;69(1):120-6.

64 Tsai CJ, Leitzmann MF, Willett WC, Giovannucci EL. Fruit and vegetable consumption and risk of cholecystectomy in women. Am J Med. 2006 Sep;119(9):760-7.

65 Nordenvall C, Oskarsson V, Wolk A. Fruit and vegetable consumption and risk of cholecystectomy: a prospective cohort study of women and men. Eur J Nutr. 2018 Feb;57(1):75-81.
66 Tsai CJ, Leitzmann MF, Willett WC, Giovannucci EL. Long-term intake of dietary fiber and decreased risk of cholecystectomy in women. Am J Gastroenterol. 2004 Jul;99(7):1364-70.

67 Morán S, Milke P, Rodríguez-Leal G, Uribe M. Gallstone formation in obese subjects undergoing a weight reduction diet. Int J Obes Relat Metab Disord. 1998 Mar;22(3):282-4.

68 Barré A, Gusto G, Cadeau C, Carbonnel F, Boutron-Ruault MC. Diet and risk of cholecystectomy: a prospective study based on the French E3N cohort. Am J Gastroenterol. 2017 Sep;112(9):1448-56.

69 Tsai CJ, Leitzmann MF, Hu FB, Willett WC, Giovannucci EL. Frequent nut consumption and decreased risk of cholecystectomy in women. Am J Clin Nutr. 2004 Jul;80(1):7681.

70 Tsai CJ, Leitzmann MF, Willett WC, Giovannucci EL. The effect of long-term intake of cis unsaturated fats on the risk for gallstone disease in men: a prospective cohort study. Ann Intern Med. 2004 Oct;141(7):514-22.

71 Tsai CJ, Leitzmann MF, Willett WC, Giovannucci EL. Long-term intake of trans-fatty acids and risk of gallstone disease in men. Arch Intern Med. 2005 May;165(9):1011-5.

72 Tsai CJ, Leitzmann MF, Willett WC, Giovannucci EL. Long-chain saturated fatty acids consumption and risk of gallstone disease among men. Ann Surg. 2008 Jan;247(1):95103

73 Berr F, Holl J, Jüngst D, Fischer S, Richter WO, Seifferth B, et al. Dietary N-3 polyunsaturated fatty acids decrease biliary cholesterol saturation in gallstone disease. Hepatology. 1992 Oct;16(4):960-7.

74 Méndez-Sánchez N, González V, Aguayo P, Sánchez JM, Tanimoto MA, Elizondo J, et al. Fish oil (n-3) polyunsaturated fatty acids beneficially affect biliary cholesterol nucleation time in obese women losing weight. J Nutr. 2001 Sep;131(9):2300-3.

75 Jonkers IJ, Smelt AH, Ledeboer M, Hollum ME, Biemond I, Kuipers F, et al. Gall bladder dysmotility: a risk factor for gall stone formation in hypertriglyceridaemia and reversal on triglyceride lowering therapy by bezafibrate and fish oil. Gut. 2003 Jan;52(1):109-15.

76 Attili AF, Scafato E, Marchioli R, Marfisi RM, Festi D. Diet and gallstones in Italy: the crosssectional MICOL results. Hepatology. 1998 Jun;27(6):1492-8.

77 Leitzmann MF, Giovannucci EL, Rimm EB, Stampfer MJ, Spiegelman D, Wing AL, et al. The relation of physical activity to risk for symptomatic gallstone disease in men. Ann Intern Med. 1998 Mar;128(6):417-25.
78 Leitzmann MF, Rimm EB, Willett WC, Spiegelman D, Grodstein F, Stampfer MJ, et al. Recreational physical activity and the risk of cholecystectomy in women. N Engl J Med. 1999 Sep;341(11):777-84.

79 Storti KL, Brach JS, FitzGerald SJ, Zmuda JM, Cauley JA, Kriska AM. Physical activity and decreased risk of clinical gallstone disease among post-menopausal women. Prev Med. 2005 Sep-Oct;41(3-4):772-7.

80 Utter AC, Whitcomb DC, Nieman DC, Butterworth DE, Vermillion SS. Effects of exercise training on gallbladder function in an obese female population. Med Sci Sports Exerc. 2000 Jan;32(1):41-5.

81 Ko CW, Napolitano PG, Lee SP, Schulte SD, Ciol MA, Beresford SA. Physical activity, maternal metabolic measures, and the incidence of gallbladder sludge or stones during pregnancy: a randomized trial. Am J Perinatol. 2014 Jan;31(1):39-48.

82 Williams C, Gowan R, Perey BJ. A doubleblind placebo-controlled trial of ursodeoxycholic acid in the prevention of gallstones during weight loss after vertical banded gastroplasty. Obes Surg. 1993 Aug;3(3):257-9.

83 Worobetz LJ, Inglis FG, Shaffer EA. The effect of ursodeoxycholic acid therapy on gallstone formation in the morbidly obese during rapid weight loss. Am J Gastroenterol. 1993 Oct;88(10):1705-10.

84 Wudel LJ Jr, Wright JK, Debelak JP, Allos TM, Shyr Y, Chapman WC. Prevention of gallstone formation in morbidly obese patients undergoing rapid weight loss: results of a randomized controlled pilot study. J Surg Res. 2002 Jan;102(1):50-6.

85 Miller K, Hell E, Lang B, Lengauer E. Gallstone formation prophylaxis after gastric restrictive procedures for weight loss: a randomized double-blind placebo-controlled trial. Ann Surg. 2003 Nov;238(5):697-702.

86 Villegas L, Schneider B, Provost D, Chang C, Scott D, Sims T, et al. Is routine cholecystectomy required during laparoscopic gastric bypass? Obes Surg. 2004 Feb;14(2):206-11.

87 Ellner SJ, Myers TT, Piorkowski JR, Mavanur AA, Barba CA. Routine cholecystectomy is not mandatory during morbid obesity surgery. Surg Obes Relat Dis. 2007 JulAug;3(4):456-60.

88 Coupaye M, Calabrese D, Sami O, Msika S, Ledoux S. Evaluation of incidence of cholelithiasis after bariatric surgery in subjects treated or not treated with ursodeoxycholic acid. Surg Obes Relat Dis. 2017 Apr;13(4):681-5.

89 Pizza F, D’Antonio D, Lucido FS, Tolone S, Del Genio G, Dell'Isola C, et al. The role of ursodeoxycholic acid (UDCA) in cholelithiasis management after one anastomosis gastric bypass (OAGB) for morbid obesity: results of a monocentric randomized controlled trial. Obes Surg. 2020 Nov;30(11):4315-24. 